\title{
Influence of chronic obstructive pulmonary disease on postoperative lung function and complications in patients undergoing operations for primary non-small cell lung cancer
}

\author{
Dragan R. Subotic, MD, PhD, ${ }^{a}$ Dragan V. Mandaric, MD, PhD, ${ }^{a}$ Tatjana M. Eminovic, MD, ${ }^{a}$ Milan M. Gajic, MS, \\ Natasa M. Mujovic, MD, ${ }^{a}$ Nikola D. Atanasijadis, MD, ${ }^{\text {a }}$ Predrag P. Dzeletovic, MD, ${ }^{\text {a } L j i l j a n a ~ D . ~ A n d r i c, ~ M D, ~}{ }^{a}$ \\ Branka M. Bulajic, MD, ${ }^{a}$ Ivan D. Dimitrijevic, MD, PhD, and Dragana P. Sobic, MD, PhD ${ }^{\mathrm{c}}$
}

From the Institutes for Lung Diseases ${ }^{\mathrm{a}}$ and Nuclear Medicine, ${ }^{\mathrm{c}}$ Clinical Center of Serbia, and Institute for Medical Statistics, Faculty of Medicine, ${ }^{\mathrm{b}}$ Belgrade, Serbia.

Received for publication Feb 28, 2007; revisions received July 20, 2007; accepted for publication July 26, 2007

Address for reprints: Dragan Subotic, MD, $\mathrm{PhD}$, Institute for Lung Diseases, Clinical Center of Serbia, 11000 Belgrade, Serbia (E-mail: vilusi@yubc.net).

J Thorac Cardiovasc Surg 2007;134:1292-9 $0022-5223 / \$ 32.00$

Copyright $\odot 2007$ by The American Association for Thoracic Surgery

doi:10.1016/j.jtcvs.2007.07.038
Objectives: Recent data have suggested that there is a flexibility of borderline values of lung function tests in allowing safe lung resection. The aim of this study was to assess the pattern of postoperative lung function change in patients with chronic obstructive pulmonary disease compared with that of patients with normal lung function, and to compare the operative morbidity and mortality between these groups.

Methods: The study included 35 patients with chronic obstructive pulmonary disease and a control group of 47 patients with normal lung function who underwent lung resection for non-small cell lung cancer. The percent changes of lung function parameters after lung resection and operative morbidity and mortality were compared between groups.

Results: The mean postoperative loss in forced expiratory volume in the 1st second was significantly less in patients with chronic obstructive pulmonary disease who underwent lobectomy compared with that of patients with normal lung function $(11.88 \%$ vs $24.6 \%, P<.05)$; forced expiratory flows at low lung volumes $(50 \%$ and $25 \%$ ) improved in patients who underwent lobectomy. The lung function change after pneumonectomy followed the same trend as that after lobectomy. In patients with chronic obstructive pulmonary disease, forced expiratory volume in the 1st second and small airways function significantly improved after preoperative bronchodilator therapy. In the group with chronic obstructive pulmonary disease, operative mortality was 0 and operative morbidity was $51.43 \%$.

Conclusions: Because the pattern of lung function change is different in patients with chronic obstructive pulmonary disease compared with that of patients with normal lung function, surgery can be offered to carefully selected patients with lung cancer, even in the presence of severely limited lung function.

$\mathrm{R}$ espiratory function directly influences the extent of lung resection. Whereas the extent of resection directly influences the prognosis in patients with lung cancer, respiratory function also has a direct effect on survival. Lung resection in patients with chronic obstructive pulmonary disease (COPD) has been recognized as a major surgical challenge. In addition to the increased lung cancer morbidity among patients with COPD, there is some evidence that COPD may also be an obstacle in the diagnosis of lung cancer, making this association even more complex. ${ }^{1}$

The percent values of forced expiratory volume in the 1st second $\left(\mathrm{FEV}_{1}\right)$, the Tiffeneau index (100 $\mathrm{FEV}_{1}$ /vital capacity $\left.[\mathrm{VC}]\right)$, and the $\mathrm{VC}$ are now accepted as 


\section{Abbreviations and Acronyms}

$\mathrm{COPD}=$ chronic obstructive pulmonary disease

$\mathrm{DLCO}=$ carbon monoxide diffusion capacity in the lung

$\mathrm{FEF}=$ forced expiratory flow

$\mathrm{FEV}_{1}=$ forced expiratory volume in the 1 st second

$\mathrm{VC}=$ vital capacity

limiting values for resection, ${ }^{2}$ instead of the absolute values used 15 years ago. Even if the $\mathrm{FEV}_{1}$ and $100 \mathrm{FEV}_{1} / \mathrm{VC}$ values are less than $60 \%$ and $50 \%$, respectively, resection should be not be rejected in a patient without previous calculation of the predicted postoperative $\mathrm{FEV}_{1}$, usually by performing perfusion lung scintigraphy. ${ }^{3}$

In patients with limited lung function, any benefit from a possible cure must be weighed against the risk of long-term disability or death. Despite much data, there is still no single test to provide the answer in individual cases. ${ }^{4}$ It was recently shown that increased carbon monoxide diffusion in the lung (DLCO) during effort is one of the most reliable methods to predict postoperative complications. An increase in DLCO of less than $10 \%$ was associated with a complication rate of $100 \%$, whereas an increase in DLCO of more than $10 \%$ from rest to $70 \%$ of maximal workload (expressed as a percent of the predicted DLCO at rest) was associated with a complication rate of $10 \% .^{5}$ It is also well established that the cutoff value of $15 \mathrm{~mL} / \mathrm{kg} / \mathrm{min}$ for oxygen consumption in effort is the best predictor of the overall operative risk. ${ }^{6}$

Although controlled studies of lung resection in patients with limited lung function are relatively rare, recent data confirmed a different pattern of postoperative lung function change in patients with COPD compared with that of patients with normal lung function. These data, despite methodologic heterogeneity, suggest that lower limits for lung function tests for safe lung resection are flexible and that lung resection can sometimes be offered to patients in whom surgery is rejected. ${ }^{7}$

The aim of this study was to 1) assess the pattern of postoperative lung function change in patients with limited lung function compared with patients with normal lung function; 2) compare operative morbidity and mortality between these groups; and 3) assess the contribution of combined bronchodilator therapy to the outcome of the treatment of patients with COPD.

\section{Materials and Methods \\ Patient Characteristics}

The prospective study included 35 patients with limited respiratory function who underwent lung resection for primary non-small cell lung cancer in a 2 -year period. There were 28 men and 7 women (M:F ratio 4:1). The age of the patients was 45 to 72 years (median
TABLE 1. Structure of analyzed groups

\begin{tabular}{lcc}
\hline & Main group & Control group \\
\hline No. of patients & 35 & 47 \\
M:F & $4: 1$ & $5.8: 1$ \\
Age $(y)$ & & \\
$\quad<40$ & 0 & $2(4.26 \%)$ \\
$41-60$ & $20(57.1 \%)$ & $28(59.57 \%)$ \\
$>60$ & $15(42.9 \%)$ & $17(36.57 \%)$ \\
Lung resection & $25(3 s$ leeve) & \\
$\quad$ Lobectomy & 10 & 22 \\
$\quad$ Pneumonectomy & & 25 \\
\hline
\end{tabular}

age of 57 years). There were 20 patients $(57.1 \%)$ aged 40 to 60 years and 15 patients $(42.9 \%)$ aged more than 60 years. Rightsided tumors were present in 21 patients $(60 \%)$, and left-sided tumors were present in 14 patients (40\%). The demographics of the study and control groups are presented in Table 1.

Only patients with a diagnosis of COPD based on GOLD criteria $^{8}$ were included in the study. Patients were classified in the COPD group if $100 \mathrm{FEV}_{1} / \mathrm{VC}$ was less than $70 \%$; mild, moderate, severe, and very severe COPD corresponds to an $\mathrm{FEV}_{1}$ greater than $80 \%, 50 \%$ to $80 \%, 30 \%$ to $50 \%$, and less than $30 \%$, respectively.

In the analyzed group, obstructive, restrictive, and mixed ventilatory disorders were present on admission in 32 patients (91.4\%), 2 patients $(5.7 \%)$, and 1 patient (2.9\%), respectively. Grading of severity of the COPD was based on GOLD criteria. Of 32 patients with COPD, moderate disease was observed in 20 patients, and severe disease was observed in 12 patients. Absolute and percent values of $\mathrm{FEV}_{1}$ and $\mathrm{VC}$ were below limiting values for direct referral to surgery in 2 patients with restrictive ventilatory disorders on admission; dominantly obstructive ventilatory disorders were observed with an $\mathrm{FEV}_{1}$ of $45 \%$ of predicted in 1 patient with mixed disorders. Thus, 27 patients $(77.14 \%)$ in the analyzed group had moderate to severe COPD according to GOLD criteria.

Lobectomy was performed in 25 patients $(71.4 \%)$, and pneumonectomy was performed in 10 patients $(28.6 \%)$. A right upper (3-sleeve) lobectomy was performed in 9 patients, a right lower lobectomy was performed in 6 patients, and a middle lobectomy was performed in 1 patient. A left upper lobectomy was performed in 3 patients, and a left lower lobectomy was performed in 4 patients. Lobectomy associated with chest wall resection was performed in 2 patients. Left and right-sided operations were equally distributed in 10 patients with pneumonectomy.

No significant comorbidity was observed in 19 patients (54.28\%) in the analyzed group. Accompanying cardiovascular diseases were demonstrated in 7 patients (20\%) (cardiac arrhythmia in 5 patients, myocardiopathy with arrhythmia in 1 patient, and previous myocardial infarction in 1 patient). Two patients $(5.71 \%)$ had diabetes, arterial hypertension, and gastric ulcer. In the remaining 3 patients $(8.58 \%)$, less significant comorbidity was observed.

The control group consisted of 47 patients with normal lung function who underwent lung resection for non-small cell lung cancer. The mean age of patients was 63.95 years, with 2 patients $(4.26 \%)$ aged less than 40 years, 28 patients $(59.57 \%)$ aged 50 to 60 years, and 17 patients (36.57\%) aged more than 60 years. In this 
TABLE 2. Lung function changes in patients with limited and normal lung function after lobectomy

\begin{tabular}{|c|c|c|c|c|c|c|}
\hline & \multicolumn{3}{|c|}{ Limited lung function } & \multicolumn{3}{|c|}{ Normal lung function } \\
\hline & Mean & SD & Median & Mean & SD & Median \\
\hline Preoperative $\mathrm{FEV}_{1}$ & 1598.8 & 391.56 & 1640 & 2852.27 & 479.34 & 2640 \\
\hline Preoperative $\mathrm{FEF}_{50}$ & 22.95 & 10.91 & 22.0 & 64.64 & 16.94 & 62.50 \\
\hline Preoperative $\mathrm{FEF}_{25}$ & 25.42 & 13.30 & 23.50 & 58.77 & 17.23 & 59.0 \\
\hline$\Delta \mathrm{FEV}_{1}$ & 11.88 & 12.94 & 9.78 & 24.60 & 11.06 & 26.65 \\
\hline$\Delta \mathrm{FEF}_{25}$ & -25.59 & 81.56 & 10.00 & 16.38 & 32.47 & 23.53 \\
\hline
\end{tabular}

$S D$, Standard deviation; $F E V_{1}$, forced expiratory volume in the 1st second; $F E F$, forced expiratory flow; $V C$, vital capacity. $\Delta$ FEV ${ }_{1}:$ percent difference between $\mathrm{FEV}_{1}(\mathrm{~mL})$ before versus $\mathrm{FEV}_{1}(\mathrm{~mL})$ after lobectomy. $\Delta \mathrm{VC}$ : percent difference between $\mathrm{VC}(\mathrm{mL})$ before versus $\mathrm{VC}$ (mL) after lobectomy. $\Delta \mathrm{FEF}_{50}$ : percent difference between $\mathrm{FEF}_{50}(\%)$ before versus $\mathrm{FEF}_{50}(\%)$ after lobectomy. $\Delta \mathrm{FEF}_{25}$ : percent difference between $\mathrm{FEF}_{25}(\%)$ before versus $\mathrm{FEF}_{25}(\%)$ after lobectomy. (l:n): patients with limited lung function versus patients with normal lung function.

group, lobectomy was performed in 22 patients and pneumonectomy was performed in 25 patients. There were 5 right upper and 4 right lower lobectomies, and 1 patient underwent a middle lobectomy. In patients with left-sided tumors, 6 upper and 5 lower lobectomies were performed, and 1 patient underwent lobectomy with a chest wall resection. In patients with pneumonectomy, there were 6 right-sided and 19 left-sided operations.

\section{Preoperative Workup}

On the basis of the respiratory function test results on admission, all patients in the main group received combined bronchodilator therapy consisting of intravenous administration of theophylline derivatives twice per day (daily dose $2 \times 25 \mathrm{mg}$ or $2 \times 12.5 \mathrm{mg}$ ) and inhaled bronchodilators 2 to 3 times per day. Physiotherapy was applied in all patients in the preoperative period (aerosol therapy, breathing and chest wall-expanding exercises, techniques of the forced expiration) and early postoperative period (improvement of the peripheral circulation, techniques of diaphragmatic breathing, inhalations, and expectoration with the aid of the therapist).

Control spirometry was performed 7 to 10 days after initiation of the treatment. Patients with $\mathrm{FEV}_{1}$ and $100 \mathrm{FEV}_{1} / \mathrm{VC}$ greater than $60 \%$ at control spirometry and without auscultatory signs of obstruction of the air-flow on physical examination were referred directly to surgery. Nine patients in the analyzed group, with $\mathrm{FEV}_{1}$ and $100 \mathrm{FEV}_{1} / \mathrm{VC}$ less than $60 \%$ at control spirometry, underwent perfusion scintigraphy of the lungs with quantification of the perfusion of each lung to calculate the predicted postoperative $\mathrm{FEV}_{1}$. They were referred to surgery because their postoperative $\mathrm{FEV}_{1}$ was greater than $30 \%$ of predicted. The calculation of the postoperative $\mathrm{FEV}_{1}$ was performed by using the stepwise method proposed by Bolliger and colleagues, ${ }^{9}$ consisting of calculating the predicted loss of lung function and subtracting the obtained value from the measured preoperative $\mathrm{FEV}_{1}$ value.

\section{Data Analysis}

The type of ventilatory disorder was correlated to different categories of radiographic and bronchoscopic findings. Preoperative absolute and percent values of $\mathrm{FEV}_{1}, \mathrm{VC}$, forced expiratory flows at $50 \%$ and $25 \% \mathrm{VC}\left(\mathrm{FEF}_{50}\right.$ and $\left.\mathrm{FEF}_{25}\right)$, and $100 \mathrm{FEV}_{1} / \mathrm{VC}$ were compared with their postoperative values. The differences between preoperative and postoperative values of $\mathrm{FEV}_{1}, \mathrm{VC}, \mathrm{FEF}_{50}$, and $\mathrm{FEF}_{25}$ were calculated and statistically analyzed depending on the extent of the lung resection (lobectomy vs pneumonectomy).

The differences among $\mathrm{FEV}_{1}, \mathrm{VC}, \mathrm{FEF}_{50}, \mathrm{FEF}_{25}$, and 100 $\mathrm{FEV}_{1} / \mathrm{VC}$ on admission and after combined bronchodilator therapy were calculated and statistically analyzed for the entire group and according to the bronchoscopic aspect. The group of patients with limited lung function was compared with the control group in terms of perioperative mortality and morbidity (death or complications within 30 days after the operation). The paired-samples $t$ test, Mann-Whitney $U$ test, and chi-square test were used.

\section{Results}

Ventilatory Disorders and Bronchoscopic Aspect

In patients with obstructive disorders, no endobronchial or extrabronchial tumor growth was observed in 17 patients $(53.1 \%)$; endobronchial tumor growth was observed in 8 patients $(25 \%)$, and infiltrative stenosis of the bronchus was observed in 7 patients $(21.9 \%)$. Endobronchial tumor growth was observed in 1 of 2 patients with restrictive disorders, and no visible tumor growth was observed in 1 patient.

\section{Postoperative Lung Function Changes}

A comparison of patients with limited lung function and patients with normal lung function, related to lung function changes after lobectomy, is presented in Table 2. In 3 patients with limited lung function, $\mathrm{FEV}_{1}$ significantly improved after lobectomy compared with preoperative values $(34.7 \%, 38.2 \%$, and $39.6 \%)$, probably because of the lungvolume reduction effect. In the rest of the patients, the mean postoperative decrease in $\mathrm{FEV}_{1}$, expressed as percent decrease related to preoperative values, was $11.88 \%$ versus a $24.6 \%$ decrease in patients with lobectomy and normal lung function $(P<.05)$. 
TABLE 3. Perfusion scans in three patients with improved forced expiratory volume at 1 second postoperatively

\begin{tabular}{ccccc}
\hline & \multicolumn{2}{c}{$\%$ Perfusion } & & \\
\cline { 2 - 4 } $\begin{array}{l}\text { Patient } \\
\text { No. }\end{array}$ & $\begin{array}{c}\text { Diseased } \\
\text { lung }\end{array}$ & $\begin{array}{c}\text { Healthy } \\
\text { lung }\end{array}$ & PD (\%)* & $\begin{array}{c}\text { PD corresponds } \\
\text { to tumor } \\
\text { localization }\end{array}$ \\
\hline 1 & 42 & 58 & 14.2 & Yes \\
2 & 47 & 53 & 32 & Yes \\
3 & 45.8 & 54.2 & 15 & Yes \\
\hline
\end{tabular}

$P D$, Perfusion defect. *Perfusion defect expressed as percent of perfusion of the ipsilateral lung.

The postoperative change in VC followed the same pattern, but the mean postoperative decrease of $15.69 \%$ in patients with limited lung function was not significantly lower compared with the mean VC decrease of $20.6 \%$ in patients with normal lung function.

In patients with limited lung function, FEF at low lung volumes $\left(\mathrm{FEF}_{50}, \mathrm{FEF}_{25}\right)$ improved after lobectomy. In patients with normal lung function, both $\mathrm{FEF}_{50}$ and $\mathrm{FEF}_{25}$ decreased after lobectomy. The $18.14 \%$ improvement of $\mathrm{FEF}_{50}$ in the main group was statistically significant. In patients with COPD, a $25.59 \%$ increase in $\mathrm{FEF}_{25}$ after lobectomy was not statistically significant.

The perfusion pattern of 3 patients whose $\mathrm{FEV}_{1}$ improved postoperatively is presented in Table 3 . In all 3 of these patients, perfusion defects corresponded to the tumorbearing lobes, representing $14.2 \%, 32 \%$, and $15 \%$ of the total perfusion of the diseased lungs. Tumor perfusion defects were localized in the left lower lobe (patient 1), right upper lobe (patient 2), and right middle-lower lobe (patient 3). Also, in all 3 patients, the perfusion of the healthy lung was better compared with that of the diseased lung.
A comparison between patients with limited and normal lung function, related to lung function changes after pneumonectomy, is presented in Table 4 .

The pattern of lung function change after pneumonectomy in patients with limited lung function followed the same trend as that after lobectomy: significantly smaller decrease in $\mathrm{FEV}_{1}$ compared with the control group (17.88\% vs $42.51 \%$ ) and evidently (but not significantly) smaller decrease in $\mathrm{VC}$ and improvement of $\mathrm{FEF}_{50}$ and $\mathrm{FEF}_{25}$. In patients who underwent a pneumonectomy, the $23.31 \%$ mean improvement of $\mathrm{FEF}_{50}$ in those with COPD was not statistically significant. The $\mathrm{FEV}_{1}$ at $25 \% \mathrm{VC}$ also improved in the main group, but the differences between groups were not significant.

In 8 patients who underwent a pneumonectomy, we analyzed the differences between predicted $\mathrm{FEV}_{1}$ based on ventilation/perfusion scans and $\mathrm{FEV}_{1}$ measured postoperatively, expressed as \pm percent differences related to predicted postoperative $\mathrm{FEV}_{1}$. Differences between predicted and measured values of less than $5 \%, 6 \%$ to $10 \%, 11 \%$ to $20 \%$, and more than $20 \%$ were observed in $2,1,2$, and 3 patients, respectively.

\section{Lung Function Changes After Combined Bronchodilator Therapy}

The differences between values of ventilatory parameters before and after bronchodilator therapy are presented in Table 5. Both the mean improvement of $\mathrm{FEV}_{1}$ in milliliters $(416.6 \mathrm{~mL})$ and the $\mathrm{FEV}_{1}$ percent improvement (14.16\%) were statistically significant compared with values on admission.

Only the VC percent improvement of $13 \%$ was statistically significant related to the $\mathrm{VC}$ baseline values.

The Tiffeneau index $\left(100 \mathrm{FEV}_{1} / \mathrm{VC}\right)$ increased from a mean value of $52.3 \%$ before treatment to $57.6 \%$ after treatment $(P<.05)$, indicating the switch of the overall venti-

TABLE 4. Lung function changes in patients with limited and normal lung function after pneumonectomy

\begin{tabular}{|c|c|c|c|c|c|c|}
\hline & \multicolumn{3}{|c|}{ Limited lung function } & \multicolumn{3}{|c|}{ Normal lung function } \\
\hline & Mean & SD & Median & Mean & SD & Median \\
\hline Preoperative $\mathrm{FEV}_{1}$ & 1912 & 546.32 & 1850 & 2934.50 & 615.98 & 2690 \\
\hline Preoperative VC & 3305 & 1262.30 & 3475 & 4163 & 879.14 & 4120 \\
\hline Preoperative $\mathrm{FEF}_{50}$ & 35.42 & 19.25 & 31.65 & 63.50 & 25.15 & 57.50 \\
\hline Preoperative $\mathrm{FEF}_{25}$ & 37.90 & 22.37 & 33.05 & 64.10 & 32.38 & 54.50 \\
\hline$\Delta \mathrm{FEV}_{1}$ & 17.88 & 31.35 & 31.33 & 42.51 & 12.98 & 43.46 \\
\hline$\Delta \mathrm{VC}$ & 23.20 & 55.00 & 43.89 & 43.74 & 10.09 & 45.71 \\
\hline$\Delta \mathrm{FEF}_{50}$ & -21.31 & 84.55 & 9.38 & 36.11 & 30.63 & 45.83 \\
\hline$\Delta \mathrm{FEF}_{25}$ & -18.83 & 97.08 & -5.13 & 22.82 & 59.21 & 32.56 \\
\hline \multicolumn{7}{|c|}{$P(I: n) F V_{1}: 0.046 ; V C: 0.689 ; F F_{50}: 0.126 ; F_{25}: 0.522$} \\
\hline
\end{tabular}

$S D$, Standard deviation; $F E V_{1}$, forced expiratory volume in the 1st second; $F E F$, forced expiratory flow; $V C$, vital capacity. $\Delta \mathrm{FEV}_{1}$ : percent difference between $\mathrm{FEV}_{1}(\mathrm{~mL})$ before versus $\mathrm{FEV}_{1}(\mathrm{~mL})$ after pneumonectomy. $\Delta \mathrm{VC}$ : percent difference between VC (mL) before versus VC (mL) after pneumonectomy. $\Delta \mathrm{FEF}_{50}$ : percent difference between $\mathrm{FEF}_{50}(\%)$ before versus $\mathrm{FEF}_{50}(\%)$ after pneumonectomy. $\Delta \mathrm{FEF}_{25}$ : percent difference between $\mathrm{FEF}_{25}(\%)$ before versus $\mathrm{FEF}_{25}$ (\%) after pneumonectomy. (I:n): patients with limited lung function versus patients with normal lung function. 
TABLE 5. Lung function in patients with chronic obstructive pulmonary disease before and after bronchodilator therapy

\begin{tabular}{|c|c|c|c|c|c|}
\hline & Mean & SD & Mean $\Delta$ & $t$ & $\begin{array}{c}\text { Significance } \\
\text { (2-tailed) }\end{array}$ \\
\hline $\mathrm{FEV}_{1}(\mathrm{~mL}) \mathrm{A}$ & 1658.14 & 504.91 & -416.66 & -7.120 & .000 \\
\hline $\mathrm{FEV}_{1}(\mathrm{~mL}) \mathrm{B}$ & 2074.81 & 465.28 & & & \\
\hline $\mathrm{FEV}_{1}(\%) \mathrm{A}$ & 55.25 & 15.42 & -14.16 & -7.14 & .000 \\
\hline $\mathrm{FEV}_{1}(\%) \mathrm{B}$ & 69.41 & 14.88 & & & \\
\hline VC (\%) A & 83.94 & 22.67 & -13.05 & -4.39 & .000 \\
\hline VC $(\%) B$ & 97.00 & 14.88 & & & \\
\hline Tiffeneau A & 52.30 & 12.40 & -5.37 & -2.59 & .01 \\
\hline Tiffeneau B & 57.67 & 9.30 & & & \\
\hline $\mathrm{FEF}_{50}(\%) \mathrm{A}$ & 24.37 & 11.36 & -7.38 & -3.49 & .002 \\
\hline $\mathrm{FEF}_{50}(\%) \mathrm{B}$ & 31.75 & 12.33 & & & \\
\hline $\mathrm{FEF}_{25}(\%) \mathrm{A}$ & 26.97 & 13.87 & -5.66 & & .05 \\
\hline $\mathrm{FEF}_{25}(\%) \mathrm{B}$ & 32.64 & 14.49 & & & \\
\hline
\end{tabular}

$S D$, Standard deviation; $F E V_{1}$, forced expiratory volume in the 1st second; $F E F$, forced expiratory flow; $V C$, vital capacity. A: before therapy; $B$ : after therapy. mean $\Delta$ : mean change (in milliliters or percent).

latory disorders from moderate and severe to mild COPD or restriction.

The mean increase in $\mathrm{FEF}_{50}$ from $24.37 \% \pm 11.36 \%$ to $31.75 \% \pm 12.33 \%$ was statistically significant. The mean increase in $\mathrm{FEF}_{25}$ from $26.97 \% \pm 13.87 \%$ to $32.64 \% \pm$ $14.49 \%$ approached statistical significance $(P=.55)$.

\section{Operative Mortality and Morbidity}

In both the main and control groups, no deaths occurred within the first 30 postoperative days. In the same period, 12 of 344 patients who underwent operation died during the first 30 postoperative days, thus representing an operative mortality of $3.1 \%$.

In the group of 35 patients with limited lung function, different postoperative complications occurred in 18 patients $(51.43 \%)$. Postoperative complications occurred in 15 patients who underwent lobectomy and in 3 patients who underwent pneumonectomy. In patients who underwent lobectomy, prolonged air leak occurred in 11 patients (44\%) (associated with arrhythmia in 1 patient), pulmonary embolism occurred in 1 patient, and pneumothorax occurred in 1 patient 8 days after the removal of chest tubes when stable lung expansion was achieved. The only case of respiratory insufficiency occurred in a patient with lobectomy. Gastric stress ulcer occurred in 1 patient. Among those who underwent pneumonectomy, arrhythmia occurred in 2 patients, and bronchopleural fistula occurred in 1 patient with a left pneumonectomy.

Of a total of 19 of 35 patients (54.28\%) with no preoperative comorbidity, no postoperative complications were registered in 11 of 19 patients (57.89\%). Of 7 patients at increased cardiac risk preoperatively, the postoperative course was uneventful in only 1 patient. In the remaining 6 patients, prolonged air leak and arrhythmia occurred in 1 patient each, and both complications occurred in 1 patient.

Postoperative complications occurred in 15 patients (31.9\%) in the control group. In patients with lobectomy, prolonged air leak occurred in 4 of 22 patients (18.2\%) and arrhythmia occurred in 3 of 22 patients (13.6\%). In the pneumonectomy group, bronchopleural fistula and empyema without fistula occurred in 1 of 25 patients (4\%). Other complications included arrhythmia in 5 patients (2 with life-threatening arrhythmia) and prolonged postoperative course with elevated body temperature in 1 patient.

Potentially life-threatening cardiopulmonary complications (embolism, respiratory insufficiency, and bronchopleural fistula) occurred in 5 patients (14.3\%) in the main group and in 3 patients $(6.38 \%)$ in the control group $(P>.05)$.

\section{Discussion}

\section{Inclusion Criteria and Preoperative Workup}

Two points should be addressed when discussing surgical treatment in patients with limited lung function. First, the cutoff values and grading of severity of COPD differ throughout the literature. In some studies, COPD is defined as the percentage of predicted $\mathrm{FEV}_{1}$ less than or equal to $70 \%$ and the percentage of $\mathrm{FEV}_{1} / \mathrm{FVC}$ less than or equal to $70 \%{ }^{10,11}$ In other studies, COPD is defined by only the $\mathrm{FEV}_{1} / \mathrm{FVC}$ being less than $70 \% .{ }^{12}$ Cutoff values for preoperative $\mathrm{FEV}_{1}$ as criteria for impaired lung function vary from an $\mathrm{FEV}_{1}$ of 1 liter or less up to $80 \%$ of predicted. ${ }^{13}$ Furthermore, the influence on morbidity, mortality, and survival is analyzed between patients with COPD and patients without COPD, or between COPD subgroups (mild/ moderate) and non-COPD subgroups. ${ }^{14}$ These methodologic differences could influence the obtained results. In the present study, in addition to the fact that COPD is not the only criterion for limited lung function, in order to avoid randomly determined cutoff values, we included only patients in whom the GOLD criteria for moderate to severe COPD could be applied.

Second, although the role of smoking cessation before lung resection is still not clear, it was obligatory in the analyzed group. Tobacco smoke directly stimulates retention of secretion and atelectasis that may be life-threatening in these patients either directly (leading to worsening of oxygenation) or indirectly (by inducing cardiac arrhythmias). Furthermore, radical lymphadenectomy causes vagal denervation with possible hyposaturation even in nonsmokers, whereas the impaired lung vascularization in patients with COPD favors prolonged air leak after the operation. ${ }^{15}$ The addition of the harmful effect of the tobacco smoke to the aforementioned factors significantly influences the lung function in the immediate and early postoperative periods. Such an attitude is supported by studies suggesting that 
smoking cessation should be encouraged because it may decrease postoperative inflammation and in the long-term may decrease the risk of recurrence. ${ }^{16}$

\section{Lung Function Changes After Resection}

Postoperative changes in $\mathrm{FEV}_{1}$ and $\mathrm{VC}$ values in both the analyzed and control groups confirmed the relatively mild permanent lung function loss after lobectomy, unlike the early permanent loss in lung function of approximately $33 \%$ that occurs after pneumonectomy. ${ }^{17}$ In the analyzed group, the loss in $\mathrm{FEV}_{1}$ was significantly lower than that in the control group of patients with normal lung function, both in patients with lobectomy and pneumonectomy. A similar finding was demonstrated in a recent study performed by Baldi and colleagues. ${ }^{18}$ In 88 patients with COPD, they demonstrated that in patients with $\mathrm{COPD}$, the delayed $\mathrm{FEV}_{1}$ deficit after lobectomy was smaller compared with patients without COPD who underwent operation. Controlled studies that could explain such results are rare. One of these is a prospective study of 16 patients ${ }^{19}$ demonstrating that the initial decrease in effort tolerance was probably the result of circulatory and ventilatory disturbances, whereas the recovery after 1 month ensued because of the improvement of the ventilatory component, initially disturbed by the operative trauma to the thoracic wall. Similar results were obtained in the study by Santambrogio and colleagues ${ }^{20}$ of 42 patients with COPD and 45 patients without COPD. In this study, the decrease in $\mathrm{FEV}_{1} 6$ months after the operation in the COPD and non-COPD groups was 3.2\% and $14.9 \%$, respectively.

One of the most important results of the current study is a significant improvement of the function of small airways (ie, of the airflow at low lung volumes: $\mathrm{FEF}_{50}$ and $\mathrm{FEF}_{25}$ ) registered after lobectomy in patients with limited lung function. Although the same trend of improvement was also registered after pneumonectomy, it was statistically significant only after lobectomy. Although the postoperative change of the small airways function was not separately analyzed in most studies dealing with this problem, the obtained results are of practical interest because of the direct influence on the pattern of postoperative lung function change and the favorable influence on perioperative morbidity and mortality.

The obtained results are of interest for preoperative patient selection. Because of the aforementioned dynamics in lung function change, a select number of patients, otherwise not suitable candidates for surgery based on lung function assessment, could be offered surgery.

\section{Operative Mortality and Morbidity}

Our finding that no patients died within the first 30 postoperative days, although relatively unexpected, was registered in the period in which the overall operative mortality calculated to all lung resections was $3.1 \%$, which corresponds to most literature data. ${ }^{21,22}$ The results of studies comparing operative mortality and morbidity in patients with limited lung function are contradictory. However, most of them confirmed that patients with COPD were exposed to the increased risk of postoperative complications. In a study on 40 patients with COPD who underwent operation, the significant impairment of the gas exchange during 1-lung ventilation was demonstrated, which was more severe in the right thoracotomy than in the left thoracotomy. ${ }^{23}$ In one of the largest studies on this issue (181 patients with COPD), the operative morbidity and mortality were $42.3 \%$ and $7.9 \%$, respectively, and cardiopulmonary complications were more frequently associated with lobectomy than with pneumonectomy ( $48.3 \%$ vs $25.6 \%$, respectively). ${ }^{24}$ Other studies showed the presence of 2 or more concomitant diseases and a performance status of grade 2 or higher as essential in terms of postoperative death, but at the same time demonstrated the improvement of pulmonary function after lung resection in patients with COPD, as in the aforementioned study of Koizumi and colleagues. ${ }^{13}$ The absence of perioperative deaths in our study supports the findings of studies that did not confirm higher complication rates in patients with COPD versus those without COPD. In the aforementioned study of Santambrogio and colleagues, ${ }^{20}$ for example, no difference in operative morbidity, operative mortality, and survival was registered between 42 patients with COPD and 45 patients without COPD.

The absence of difference in operative mortality between patients with limited and normal lung function in the analyzed group may be partly explained by the improvement of the small airways function after resection and by the influence of preoperative bronchodilator therapy on the lung function, both clearly demonstrated in this study. In regard to the improvement in the small airways function, it could be one of the significant factors helping patients to overcome the initial loss of lung function in the immediate and early postoperative period by minimizing decreases in saturation that sometimes occur in patients with incomplete lung expansion immediately after resection. Our finding that prolonged air leak or arrhythmia occurred postoperatively in 6 of 7 patients at increased cardiac risk underlines the need for optimizing lung ventilation in the early postoperative course.

Although there is still some concern among clinicians in regard to the real benefit of preoperative bronchodilator therapy, our results clearly demonstrate the significant improvement of most of the lung function parameters after bronchodilator therapy. It is likely that this improvement, in both the $\mathrm{FEV}_{1}$ and the function of the small airways, act in the same way as the previously described mechanism. From the standpoint of the surgical technique, correct aerostasis is of the utmost importance in patients with COPD. 
On the other hand, the current study with an operative morbidity of $51.43 \%$ demonstrated the more frequent occurrence of postoperative complications in patients with COPD than in those without COPD, thus confirming the majority of literature data. The distribution of complications in our group was as expected, with $44 \%$ representing prolonged air leak and approximately $14.3 \%$ representing cardiorespiratory complications.

Postoperatively, priority was given to the immediate elimination of residual air and liquid collections by reinsertion of new, narrower caliber chest tubes and quick removal of large, intraoperatively inserted chest tubes. Even with such a policy, 11 patients (31.4\%) had prolonged air leak, but without major influence to the outcome of the treatment. Physiotherapy was routine in these patients, and any manifest or imminent atelectasis was solved by fiberbronchoscopic aspiration. In all patients with COPD, low-molecular-weight heparin was introduced 6 hours after the operation and continued for 6 to 7 postoperative days.

No routine bronchial stump coverage was performed after pneumonectomy in patients with limited lung function. The only bronchopleural fistula that occurred in a patient with left pneumonectomy was a consequence of an excessive dissection and a short bronchial stump with tension to the suture line rather than of impaired vascularization caused by COPD. Nevertheless, some form of bronchial stump protection, at least in patients with COPD undergoing pneumonectomy, may be recommended. ${ }^{25}$

One possible explanation for the increased operative morbidity in patients with COPD may be found in a recent study performed at The University of Texas Health Science Center in Houston on 1334 patients who underwent operation. In this study, $41 \%$ of patients with an $\mathrm{FEV}_{1}$ of $60 \%$ to $80 \%$ had a postoperative $\mathrm{FEV}_{1}$ of less than $40 \%$, and $26 \%$ of patients had a postoperative $\mathrm{FEV}_{1}$ of less than $35 \%$. Approximately one third of patients with an $\mathrm{FEV}_{1}$ of more than 2 liters would have been deemed ineligible for pneumonectomy on the basis of a postoperative $\mathrm{FEV}_{1}$ of less than $40 \% .^{26}$ Because split-lung function tests are not routinely performed in many centers, even in patients with an $\mathrm{FEV}_{1}$ of less than $60 \%$, overestimation of postoperative lung function may be one of the causes of the increased postoperative morbidity.

\section{Conclusions}

This study demonstrated a different pattern of lung function change after lung resection between patients with limited lung function and patients with normal lung function. In patients with COPD, the loss of $\mathrm{FEV}_{1}$ was significantly smaller, whereas the function of the small airways improved after lung resection compared with patients with normal lung function. Surgery should not be rejected for patients with lung cancer and limited lung function unless additional lung function assessment is performed. Operative mortality and morbidity in patients with COPD are comparable to those in patients with normal lung function.

\section{References}

1. Maskey-Warzechowska M, Domagaa-Kulawik J, Rubinsztajn R, Chazan R. Lung cancer in COPD - a clinical analysis. Pol Arch Med Wewn. 2002;108:769-75.

2. Bolliger CT, Perruchoud AP. Functional evaluation of the lung resection candidate. Eur Respir J. 1998;11:198-212.

3. Kearney DJ, Lee TH, Reilly J, et al. Assessment of operative risk in patients undergoing lung resection. Importance of predicted pulmonary function. Chest. 1994;105:753-9.

4. Robles AM, Shure D. Optimization of lung function before pulmonary resection: pulmonologists' perspectives. Thorac Surg Clin. 2004;14: 295-304.

5. Wang JS, Abboud RT, Evans KG, Finley RJ, Graham BL. Role of CO diffusing capacity during exercise in the preoperative evaluation for lung resection. Am J Respir Crit Care Med. 2000;162:1435-44.

6. Bechard D, Wetstein L. Assessment of exercise oxygen consumption as preoperative criterion for lung resection. Ann Thorac Surg. 1987; 44:344-9.

7. Nezu K, Kushibe K, Toyo T, Takahama M, Kitamura S. Recovery and limitation of exercise capacity after lung resection for lung cancer. Chest. 1998;113:1511-6.

8. Pauwels R, Buist A, Calverley P, Jenkins C, Hurd S. Global strategy for the diagnosis, management, and prevention of chronic obstructive pulmonary disease. NHLBI/WHO Global Initiative for Chronic Obstructive Lung Disease (GOLD) Workshop summary. Am J Respir Crit Care Med. 2001;163:1256-76.

9. Bolliger CT, Guckel C, Engel H, et al. Prediction of functional reserves after lung resection: comparison between quantitative computed tomography, scintigraphy, and anatomy. Respiration. 2002;69: 482-9.

10. Sekine Y, Kesler KA, Behnia M, Brooks-Brunn J, Sekine E, Brown JW. COPD may increase the incidence of refractory supraventricular arrhythmias following pulmonary resection for non-small cell lung cancer. Chest. 2001;120:1783-90.

11. Sekine Y, Iwata T, Chiyo M, et al. Minimal alteration of pulmonary function after lobectomy in lung cancer patients with chronic obstructive pulmonary disease. Ann Thorac Surg. 2003;76:356-61.

12. López-Encuentra A, Astudillo J, Cerezal J, Gonzalez-Aragoneses F, Novoa N, Sánchez-Palencia A. Prognostic value of chronic obstructive pulmonary disease in 2994 cases of lung cancer. Eur J Cardiothorac Surg. 2005;27:8-13.

13. Koizumi K, Haraguchi S, Hirata T, et al. Surgical treatment for lung cancer patients with poor pulmonary function. Ann Thorac Cardiovasc Surg. 2005;11:87-92.

14. Nomori H, Watanabe K, Ohtsuka T, Naruke T, Suemasu K. Sixminute walking and pulmonary function test outcomes during the early period after lung cancer surgery with special reference to patients with chronic obstructive pulmonary disease. Jpn J Thorac Cardiovasc Surg. 2004;52:113-9.

15. Favier R, Kepenkian G, Desplanches D, Flandrois R. Effects of chronic lung denervation on breathing pattern and respiratory gas exchange during hypoxia, hypercapnia and exercise. Respir Physiol. 1982;47:107-19.

16. Robles AM, Shure D. Optimization of lung function before pulmonary resection: pulmonologists' perspectives. Thorac Surg Clin. 2004;14: 295-304.

17. Schuurmans MM, Diacon AH, Bolliger CT. Functional evaluation before lung resection. Clin Chest Med. 2002;23:159-72.

18. Baldi S, Ruffini E, Harari S, et al. Does lobectomy for lung cancer in patients with chronic obstructive pulmonary disease affect lung function? A multicenter national study. J Thorac Cardiovasc Surg. 2005;130: 1616-22.

19. Miyoshi S, Yoshimasu T, Hirai T, et al. Exercise capacity of thoracotomy patients in the early postoperative period. Chest. 2000;118:384-90. 
20. Santambrogio L, Nosotti M, Baisi A, Ronzoni G, Bellaviti N, Rosso L. Pulmonary lobectomy for lung cancer: a prospective study to compare patients with forced expiratory volume in $1 \mathrm{~s}$ more or less than $80 \%$ of predicted. Eur J Cardiothorac Surg. 2001;20:684-7.

21. Wahi R, McMurtrey MJ, DeCaro LF, et al. Determinants of perioperative morbidity and mortality after pneumonectomy. Ann Thorac Surg. 1989;48:33-7.

22. Tedder M, Anstadt MP, Tedder SD, Lowe JE. Current morbidity, mortality and survival after bronchoplastic procedures for malignancy. Ann Thorac Surg. 1992;54:387-91.

23. Ribas J, Jimenez MJ, Barbera JA, et al. Gas exchange and pulmonary hemodynamics during lung resection in patients at increased risk: relationship with preoperative exercise testing. Chest. 2001;120:852-9.

24. Mayo Y, Zhang D, Zhang R, et al. Surgical treatment of lung cancer patients with poor pulmonary function. Zhonghua Zhong Liu Za Zhi. 2002;24:300-2.

25. Lardinois D, Horsch A, Krüger T, Dusmet M, Ris HB. Mediastinal reinforcement after induction therapy and pneumonectomy: comparison of intercostal muscle versus diaphragm flap. Eur J Cardiothorac Surg. 2002;21:74-8.

26. Ersoy MY, Keus L, Baser S, et al. Comparing algorithms for the preoperative functional assessment of patients with lung cancer. Chest. 2005;128:170S. 